\title{
Mangrove Conservation in the Coastal Areas of Lala, Lanao del Norte, Philippines: Management Strategies and Impacts on the Status of the Mangrove Forest
}

\author{
Baclado, A.M.1, Tatil, W.T. ${ }^{2 *}$ \\ ${ }^{1}$ MS Environmental Science, Department of Biological Sciences, College of Science and \\ Mathematics, Mindanao State University - Iligan Institute of Technology, Philippines \\ ${ }^{2}$ Department of Biological Sciences, College of Science and Mathematics, Mindanao State \\ University - Iligan Institute of Technology, Philippines \\ *wella.tatil@g.msuiit.edu.ph
}

\begin{abstract}
Mangroves is one of the most threatened and rapidly disappearing natural ecosystem worldwide. In 2007, the Food and Agriculture Organization (FAO) reported that global mangrove coverage had declined from 18.8 million ha in 1980 to 15.2 million ha by the end of 2005. In the Philippines, the total recorded mangrove area is approximately 450,000 ha in early 1900's. However, these mangrove forests were constantly subjected to immense pressures of human-induced degradations such as illegal logging and conversion to fish and shrimp ponds, leaving only 117,700 ha in 1995, in effect causing the decline of fishery resources. Hence, the Philippine Government is taking efforts to rehabilitate mangrove forest through National Greening Program (NGP) and declaring mangrove areas as protected areas throughout the country. This study therefore examined the conservation management strategies applied in the coastal areas of Lala, Lanaodel Norte, Mindanao in the Philippines. A survey was conducted using semi-structures questionnaire with 76 randomly chosen household respondents. Key informant interview were also employed to understand the management strategies used by local government. Results revealed that the knowledge of the community regarding the mangrove resource and its conservation is independent from their level of educational attainment $(\mathrm{p}=0.864)$ due to the trainings conducted by government agencies on both barangays. Likewise, the increase in awareness of the importance of mangrove resource contributed to the change in attitude and perception of the community $(\mathrm{p}=0.015)$. However, the age, gender and length of stay $(\mathrm{p}=0.006,0.026$, and 0.002, respectively) affects the community's attitude to participate in the mangrove conservation management. It was also found out in the study that the diversity of mangroves in the area is low. Therefore, it implies that although there are current management strategies to conserve the degrading forest, it still needs improvement. The policy-makers can lobby on the willingness of the community to participate since majority $(67 \%)$ of them were willing to voluntarily take part in the rehabilitation activities.
\end{abstract}

Keywords: Mangrove management, Community knowledge, Perception, Willingness to participate, Diversity

Proceedings of the $22^{\text {nd }}$ International Forestry and Environment Symposium 2017 of the Department of Forestry and Environmental Science, University of Sri Jayewardenepura, Sri Lanka 